\title{
Characteristics of B cell-associated gene expression in patients with coronary artery disease
}

\author{
WENWEN YAN* ${ }^{*}$ HAOMING SONG* ${ }^{*}$ JINFA JIANG, WENJUN XU, ZHU GONG, \\ QIANGLIN DUAN, CHUANGRONG LI, YUAN XIE and LEMIN WANG \\ Department of Internal Medicine, Division of Cardiology, Tongji Hospital, \\ Tongji University School of Medicine, Shanghai 200065, P.R. China
}

Received May 19, 2015; Accepted February 12, 2016

DOI: $10.3892 / \mathrm{mmr} .2016 .5029$

\begin{abstract}
The current study aimed to identify differentially expressed B cell-associated genes in peripheral blood mononuclear cells and observe the changes in B cell activation at different stages of coronary artery disease. Groups of patients with acute myocardial infarction (AMI) and stable angina (SA), as well as healthy volunteers, were recruited into the study ( $n=20$ per group). Whole human genome microarray analysis was performed to examine the expression of B cell-associated genes among these three groups. The mRNA expression levels of 60 genes associated with B cell activity and regulation were measured using reverse transcription-quantitative polymerase chain reaction. The mRNA expression of the $\mathrm{B}$ cell antigen receptor (BCR)-associated genes, CD45, NFAM, SYK and LYN, were significantly upregulated in patients with AMI; however, FCRL3, CD79B, CD19, CD81, FYN, BLK, CD22 and CD5 mRNA expression levels were significantly downregulated, compared with patients in the SA and control group. The mRNA levels of the T-independent B cell-associated genes, CD16, CD32, LILRA1 and TLR9, were significantly increased in AMI patients compared with SA and control patients. The mRNA expression of genes associated with T-dependent B cells were also measured: EMR2 and CD97 were statistically upregulated, whereas SLAMF1, LY9, CD28, CD43, CD72, ICOSL, PD1, CD40 and CD20 mRNAs were significantly downregulated in AMI group patients compared
\end{abstract}

Correspondence to: Dr Lemin Wang, Department of Internal Medicine, Division of Cardiology, Tongji Hospital, Tongji University School of Medicine, 389 Xincun Road, Putuo, Shanghai 200065, P.R. China

E-mail: wanglemin@tongji.edu.cn

*Contributed equally

Abbreviations: BCR, B cell antigen receptor; AMI, acute myocardial infarction; PBMCs, peripheral blood mononuclear cells; SA, stable angina; Ig, immunoglobulin

Key words: myocardial infarction, stable angina pectoris, B cells, gene expression, humoral immunity with the two other groups. Additionally the gene expression levels of B cell regulatory genes were measured. In patients with AMI, CR1, LILRB2, LILRB3 and VAV1 mRNA expression levels were statistically increased, whereas, CS1 and IL4I1 mRNAs were significantly reduced compared with the SA and control groups. There was no statistically significant difference in B cell-associated gene expression levels between patients with SA and the control group. The present study identified the downregulation of genes associated with BCRs, B2 cells and $\mathrm{B}$ cell regulators in patients with AMI, indicating a weakened $\mathrm{T}$ cell-B cell interaction and reduced $\mathrm{B} 2$ cell activation during AMI. Thus, improving B2 cell-mediated humoral immunity may be a potential target for medical intervention in patients with AMI.

\section{Introduction}

Atherosclerosis is a major cause of coronary artery disease, which is a leading cause of mortality in numerous countries (1). The presence of B lymphocytes during inflammatory infiltration in humans $(2,3)$ and mouse models $(4,5)$ has led to the investigation of their importance in atherosclerosis. However, the association between B cells and atherogenesis remains controversial. T-independent B cells (B1 cells) have atheroprotective properties $(6,7)$, whereas T-dependent B cells (B2 cells) exhibit pro-atherogenic activity $(8,9)$. The activation of $\mathrm{B}$ cells requires two signals. The first signal is the binding of an antigen to the $\mathrm{B}$ cell antigen receptor (BCR) expressed on the surface of B cells. If the antigen is thymus-independent, B cells can stimulate the second signal directly. However, thymus-dependent antigens require an interaction between T cells and B cells for the second signal to be initiated (10). B1 and B2 cells constitute the two predominant B cell types, and are considered to be part of the innate and adaptive immune systems, respectively (11). B1 cells are a minor group of B cells that produce natural antibodies against common microbial epitopes and self-determinants. By contrast, B2 cells are considered to be the conventional B lymphocytes, requiring signals from $\mathrm{T}$ helper cells to recognize specific antigens, and to produce and regulate antibody-mediated humoral immunity $(12,13)$.

In the present study, the expression levels of a range of $\mathrm{B}$ cell-associated genes involved in B cell activation were 
examined. Human cDNA microarray analysis was used to detect the variations in gene expression levels at different stages of B cell activation and in subsets of peripheral blood mononuclear cells (PBMCs) isolated from patients with AMI and stable angina (SA), as well as healthy controls. The in vitro study was designed to investigate differential gene expression levels in B cells, and analyze the differences in humoral immunity in patients with AMI and SA.

\section{Patients and methods}

Patient information. The current study consisted of 3 groups of subjects: 20 patients with AMI, 20 patients with SA and 20 healthy volunteers. The baseline demographic data are presented in Table I. The patients with AMI were admitted to a Coronary Care Unit of Tongji Hospital (Shanghai, China), $<12 \mathrm{~h}$ after the onset of symptoms between January and June 2013. The AMI group included 18 male and 2 female patients aged $58 \pm 12$ years [mean \pm standard deviation (SD)]. All patients with AMI were diagnosed on the basis of previously described criteria (14). Briefly, selected subjects exhibited a rise in cardiac biomarker parameters (preferably cardiac troponin) with at least one value above the 99th percentile reference limit and with at least one of the following features: i) Symptoms of ischemia; ii) new or presumed new significant ST-segment-T wave changes or new left bundle branch block; iii) development of pathological Q waves in the electrocardiograph; iv) imaging evidence of new loss of viable myocardium or new regional wall motion abnormality; and v) identification of an intracoronary thrombus by angiography.

In the SA group, 18 male and 2 female patients of age $64 \pm 10$ years (mean \pm SD) with exclusively effort-associated angina were analyzed. Each patient exhibited positive exercise stress test results and at least one coronary stenosis was detected during angiography ( $>70 \%$ reduction of lumen diameter). There was no significant difference between AMI and SA patients (Table I) regarding age, gender, smoking status, body mass index, systolic blood pressure, diastolic blood pressure, low-density lipoprotein cholesterol, high-density lipoprotein cholesterol, triglycerides or fasting glucose.

The control group consisted of 17 male and 3 female healthy volunteers of age $29 \pm 3$ years (mean \pm SD), recruited during the same time period as patients with AMI and SA. Family histories, physical examination, electrocardiograph, chest radiography and routine chemical analysis demonstrated that the controls had no evidence of coronary heart disease.

SA group candidates were outpatients with risk factors of cardiovascular disease and verified by electrocardiogram, cardio angiography or treadmill exercise test. The control candidates were individuals living in nearby communities without any risk factors or history of cardiovascular diseases. The exclusion criteria for the three groups were venous thrombosis, hematological disorders, acute or chronic inflammatory diseases, intake of hormones or immunosuppressors and malignancy.

The study protocol was approved by the ethics committee of Tongji University (Shanghai, China) and informed consent forms were obtained.
Microarraygeneexpressionanalysis.AHumanGeneExpression Microarray kit was purchased from Agilent Technologies, Inc. (cat no. G4112F; Santa Clara, CA, USA). The microarray was composed of $>41,000$ genes or transcripts, including 19,596 targeted Entrez gene RNAs. The sequence information used in the microarrays was derived from the latest databases of RefSeq (www.ncbi.nlm.nih.gov/refseq), GoldenPath (genome.ucsc.edu/index.html), Ensembl (www.ensembl.org) and Unigene (www.ncbi.nlm.nih.gov/unigene). The functions of $>70 \%$ of the genes in the microarray had been previously established. All patients were subjected to the microarray analysis.

Total RNA isolation. Peripheral blood samples $(5 \mathrm{ml})$ were collected from patients with AMI and SA in PAXgene tubes (BD Biosciences, San Jose, CA, USA) immediately after admission. The control group blood samples were collected from nearby communities during the same period as AMI/SA blood collection in the hospital. Briefly, the leukocytes were isolated through density gradient centrifugation with Ficoll solution (Sigma Aldrich, St. Louis, MO, USA) and the remaining red blood cells were destroyed with erythrocyte lysis buffer (Qiagen GmbH, Hilden, Germany). Total RNA was extracted and purified using a PAXgene Blood RNA kit (cat no. 762174; Qiagen $\mathrm{GmbH}$ ), according to the manufacturer's protocol. RNA integrity number (RIN) was measured to analyze RNA integration using an Agilent Bioanalyzer 2100 (Agilent Technologies, Inc.). Samples were considered to be high quality when RIN was $\geq 7.0$ and $28 \mathrm{~S} / 18 \mathrm{~S}$ was $\geq 1.7$.

RNA amplification and labeling. Total RNA was amplified and labeled with Cy3 using a by Low Input Quick Amp Labeling kit, one-color (cat no. 5190-2305; Agilent Technologies, Inc.) according to the manufacturer's protocol. Labeled cRNA was purified using an RNeasy Mini kit (cat no. 74106, Qiagen $\mathrm{GmbH})$.

Microarray hybridization. Each microarray slide was hybridized with $1.65 \mu \mathrm{g}$ Cy3-labeled cRNA using a Gene Expression Hybridization kit (cat no. 5188-5242) in a hybridization oven (cat no. G2545A) at $37^{\circ} \mathrm{C}$, both purchased from Agilent Technologies, Inc., according to the manufacturer's protocol. After $17 \mathrm{~h}$ of hybridization, the slides were washed in staining dishes (cat no. 121; Thermo Fisher Scientific, Inc., Waltham, MA, USA) with a Gene Expression Wash Buffer kit (cat no. 5188-5327; Agilent Technologies, Inc.), according to the manufacturer's protocol.

Microarray scanning and data acquisition. The microarray slides were scanned with an Agilent Microarray Scanner (cat no. G2565CA; Agilent Technologies, Inc.) using the default settings (dye channel, green; scan resolution, $3 \mu \mathrm{m} ; 20 \mathrm{bit}$ ). Data were extracted using Feature Extraction software (version 10.7; Agilent Technologies, Inc.). Raw data were normalized using the Quantile algorithm function of Gene Spring software (version 11.0; Agilent Technologies, Inc.).

Reverse transcription-quantitative polymerase chain reaction (RT-qPCR). The spots on the microarray were randomly selected and their mRNA expression levels were confirmed 
Table I. Baseline demographic data in AMI, SA and control groups.

\begin{tabular}{|c|c|c|c|c|c|}
\hline \multirow[b]{2}{*}{ Patient characteristic } & \multirow[b]{2}{*}{ AMI } & \multirow[b]{2}{*}{ SA } & \multirow[b]{2}{*}{ Control } & \multicolumn{2}{|c|}{ P-value } \\
\hline & & & & All groups & AMI vs. SA \\
\hline Age, years & $57.8 \pm 11.9$ & $63.6 \pm 9.9$ & $28.8 \pm 3.3$ & 0.000 & 0.251 \\
\hline Gender (male/female), $\mathrm{n}$ & $18 / 2$ & $18 / 2$ & $17 / 3$ & 0.853 & 1.000 \\
\hline Body mass index, $\mathrm{kg} / \mathrm{m}^{2}$ & $23.6 \pm 2.6$ & $22.8 \pm 2.7$ & $21.3 \pm 1.8$ & 0.102 & 0.560 \\
\hline Smoking history, n/day & $13.6 \pm 12.2$ & $9.8 \pm 10.3$ & $0 \pm 0$ & 0.000 & 0.648 \\
\hline Systolic blood pressure, $\mathrm{mmHg}$ & $128.6 \pm 15.3$ & $123.0 \pm 12.1$ & $120.8 \pm 7.2$ & 0.115 & 0.501 \\
\hline Diastolic blood pressure, $\mathrm{mmHg}$ & $67.0 \pm 8.0$ & $73.0 \pm 8.0$ & $71.6 \pm 3.2$ & 0.017 & 0.064 \\
\hline LDL-C, mmol/1 & $2.5 \pm 1.0$ & $2.1 \pm 0.8$ & $2.9 \pm 0.5$ & 0.327 & 0.548 \\
\hline Triglycerides, mmol/1 & $1.6 \pm 1.1$ & $1.5 \pm 1.4$ & $1.2 \pm 0.4$ & 0.730 & 0.762 \\
\hline HDL-C, mmol/l & $0.8 \pm 0.7$ & $0.9 \pm 0.2$ & $1.3 \pm 0.2$ & 0.000 & 0.803 \\
\hline Fasting blood glucose, $\mathrm{mmol} / \mathrm{l}$ & $5.4 \pm 0.9$ & $5.0 \pm 0.8$ & $4.9 \pm 0.5$ & 0.610 & 0.082 \\
\hline
\end{tabular}

Data are presented as the mean \pm standard deviation (excluding Gender). $n=20$ for all groups. AMI, acute myocardial infarction; SA, stable angina; LDL-C, low-density lipoprotein cholesterol; HDL-C, high-density lipoprotein cholesterol.

by RT-qPCR. Briefly, reverse transcription was performed using the iScript reverse transcription supermix kit (Bio-Rad Laboratories, Inc., Hercules, CA, USA; cat. no. 1708841). The Ambion TURBO DNA-free DNase treatment kit (Thermo Fisher Scientific, Inc., Waltham, MA, USA; cat. no. AM1907) was utilized to remove contaminating DNA from RNA preparations according to the manufacturer's instructions. Real-time PCR was performed on a CFX96 Touch Real-time PCR detection system (Bio-Rad Laboratories, Inc.; cat. no. 1855195) using the iQ SYBR Green Supermix, (Bio-Rad Laboratories, Inc.; cat. no. 1708880) according to the manufacturer's instructions. The cycling conditions for RT-qPCR were as follows: $95^{\circ} \mathrm{C}$ for $30 \mathrm{sec}, 95^{\circ} \mathrm{C}$ for $5 \mathrm{sec}, 60^{\circ} \mathrm{C}$ for $5 \mathrm{sec}$ and plate read, 40 cycles at $95^{\circ} \mathrm{C}$ for $30 \mathrm{sec}$, melting curve at $65-95^{\circ} \mathrm{C}$, increment $0.5^{\circ} \mathrm{C}$ for $5 \mathrm{sec}$ and plate read. Of the genes with differential expression levels, three were randomly selected, and these genes and a reference gene (GAPDH) were subjected to RT-qPCR. The relative expression levels were indicated as the expression of the target genes normalized to the expression of GAPDH $\left(2^{-\Delta \Delta \mathrm{Cq}}\right)$. The melting curve and the $2^{-\Delta \Delta \mathrm{Cq}}$ method (15) were used to detect differences in gene expression levels among the three groups. The results from RT-qPCR were consistent with the microarray analysis (data not shown).

Statistical analysis. Values are expressed as the mean \pm SD. A one-way analysis of variance (ANOVA) was used to examine differences between the groups. Pair-wise group comparisons following ANOVA were performed using Tukey's multiple comparison tests. Data were analyzed using SPSS version 17.0 (SPSS, Inc., Chicago, IL, USA). P $<0.05$ was considered to indicate a statistically significant difference.

\section{Results}

$m R N A$ expression levels of genes associated with BCR. The present study measured the expression levels of 22 genes associated with the BCR in patients with AMI and SA, as well as controls subjects (Table II; Fig. 1). In PBMCs from the three groups, the expression levels of 15 genes were statistically different $(\mathrm{P}<0.05)$ : CD45, NFAM1, BTK, SYK, LYN, FCRL3, CD79A, CD79B, CD19, CD21, CD81, FYN, BLK, CD22 and CD5. Compared with the control subjects, the gene expression levels of CD45, NFAM1, BTK, SYK, and LYN were significantly upregulated $(\mathrm{P}<0.05)$, whereas CD79A, CD21 $(\mathrm{P}<0.05)$, FCRL3, CD79B, CD19, CD81, FYN, BLK, CD22 and CD5 $(\mathrm{P}<0.01)$ mRNA expression were downregulated in the AMI group. In PBMCs from AMI patients, the expression of CD45, NFAM1, SYN and LYN were statistically increased $(\mathrm{P}<0.01)$, whereas FCRL3, CD79B, CD19, CD81, FYN, BLK, CD22 and $\mathrm{CD} 5$ expression were significantly reduced $(\mathrm{P}<0.05)$ compared with the levels in PBMCs from the SA group. There were no significant differences in BCR-associated mRNA expression levels between the SA and control group.

mRNA expression levels of genes associated with B1 cells. The present study measured the expression levels of 7 genes associated with B1 cell activation in PBMCs from the AMI, SA and control groups (Table III; Fig. 2). In separate comparisons, CD16, CD32, LILRA1 and TLR9 mRNA levels were significantly increased in patients with AMI compared with SA and control patients $(\mathrm{P}<0.05)$. There was no statistical difference in the expression levels of genes associated with T1 cell activation between patients with SA and the control group.

mRNA expression levels of genes associated with B2 cells. The expression levels of 20 genes associated with B2 cell activation were examined in PBMCs from patients with AMI and SA, as well as control subjects (Table IV; Fig. 3). In PBMCs from the three groups, the expression levels of the following 11 genes were statistically different $(\mathrm{P}<0.05)$ : EMR2, CD97, SLAMF1, LY9, CD28, CD43, CD72, ICOSL, PD1, CD40 and CD20. The mRNA expression levels of EMR2 and CD97 were significantly upregulated $(\mathrm{P}<0.01)$, whereas SLAMF1, LY9, CD28, CD43, CD72, ICOSL, PD1, CD40 and CD20 mRNAs were significantly downregulated $(\mathrm{P}<0.05)$, in the AMI group 
Table II. Expression of genes associated with B cell antigen receptor in B cell activation.

\begin{tabular}{|c|c|c|c|c|c|c|c|}
\hline \multirow[b]{2}{*}{ Gene ID } & \multicolumn{3}{|c|}{ Gene expression ${ }^{a}$} & \multicolumn{4}{|c|}{ P-value } \\
\hline & AMI & SA & Control & All groups & AMI vs. control & AMI vs. SA & SA vs. control \\
\hline BLK & $8.85 \pm 0.66$ & $9.39 \pm 0.52$ & $9.64 \pm 0.54$ & 0.000 & 0.000 & 0.009 & 0.359 \\
\hline BLNK & $6.31 \pm 0.37$ & $6.50 \pm 0.55$ & $6.63 \pm 0.43$ & 0.086 & 0.072 & 0.364 & 0.655 \\
\hline BTK & $8.58 \pm 0.26$ & $8.38 \pm 0.31$ & $8.33 \pm 0.32$ & 0.027 & 0.029 & 0.102 & 0.846 \\
\hline NFAM1 & $7.29 \pm 0.60$ & $6.59 \pm 0.46$ & $6.51 \pm 0.44$ & 0.000 & 0.000 & 0.000 & 0.873 \\
\hline LYN & $14.52 \pm 0.36$ & $13.74 \pm 0.45$ & $13.49 \pm 0.28$ & 0.000 & 0.000 & 0.000 & 0.099 \\
\hline CD5 & $9.26 \pm 0.52$ & $9.80 \pm 0.34$ & $9.82 \pm 0.29$ & 0.000 & 0.000 & 0.000 & 0.984 \\
\hline CD19 & $10.49 \pm 0.59$ & $11.12 \pm 0.51$ & $11.53 \pm 0.55$ & 0.000 & 0.000 & 0.002 & 0.057 \\
\hline CD21 & $9.09 \pm 1.73$ & $9.69 \pm 1.35$ & $10.23 \pm 1.00$ & 0.042 & 0.032 & 0.372 & 0.436 \\
\hline CD45 & $13.63 \pm 0.75$ & $13.01 \pm 0.48$ & $12.81 \pm 0.20$ & 0.000 & 0.000 & 0.001 & 0.233 \\
\hline CD22 & $6.38 \pm 0.55$ & $6.93 \pm 0.57$ & $7.17 \pm 0.60$ & 0.000 & 0.000 & 0.009 & 0.517 \\
\hline CD79A & $13.87 \pm 1.67$ & $14.59 \pm 1.21$ & $15.08 \pm 0.77$ & 0.014 & 0.020 & 0.339 & 0.347 \\
\hline CD79B & $8.76 \pm 0.39$ & $9.29 \pm 0.52$ & $9.51 \pm 0.44$ & 0.000 & 0.000 & 0.001 & 0.293 \\
\hline CD81 & $11.34 \pm 0.41$ & $11.84 \pm 0.33$ & $11.87 \pm 0.33$ & 0.000 & 0.000 & 0.000 & 0.962 \\
\hline FYN & $11.94 \pm 0.33$ & $12.33 \pm 0.32$ & $12.34 \pm 0.22$ & 0.000 & 0.000 & 0.000 & 0.099 \\
\hline FCRL1 & $7.08 \pm 0.42$ & $7.33 \pm 0.56$ & $7.35 \pm 0.53$ & 0.188 & 0.230 & 0.276 & 0.993 \\
\hline FCRL2 & $7.60 \pm 0.38$ & $7.80 \pm 0.49$ & $8.00 \pm 0.49$ & 0.180 & 0.154 & 0.670 & 0.566 \\
\hline FCRL3 & $7.43 \pm 0.68$ & $7.96 \pm 0.59$ & $8.04 \pm 0.52$ & 0.004 & 0.006 & 0.020 & 0.892 \\
\hline FCRL4 & $2.66 \pm 1.15$ & $2.70 \pm 0.81$ & $2.81 \pm 1.15$ & 0.901 & 0.899 & 0.993 & 0.944 \\
\hline FCRL5 & $5.39 \pm 0.82$ & $5.57 \pm 0.68$ & $5.64 \pm 0.81$ & 0.607 & 0.597 & 0.765 & 0.960 \\
\hline LAX & $5.85 \pm 0.55$ & $6.12 \pm 0.70$ & $5.90 \pm 0.63$ & 0.365 & 0.982 & 0.390 & 0.493 \\
\hline PIR & $3.12 \pm 1.01$ & $2.47 \pm 0.51$ & $2.69 \pm 0.53$ & 0.106 & 0.054 & 0.273 & 0.456 \\
\hline SYK & $12.26 \pm 0.25$ & $11.94 \pm 0.31$ & $11.87 \pm 0.21$ & 0.000 & 0.000 & 0.001 & 0.802 \\
\hline
\end{tabular}

${ }^{\text {aD }}$ ata are presented as the mean \pm standard deviation. $\mathrm{n}=20$ for all groups. AMI, acute myocardial infarction; SA stable angina.

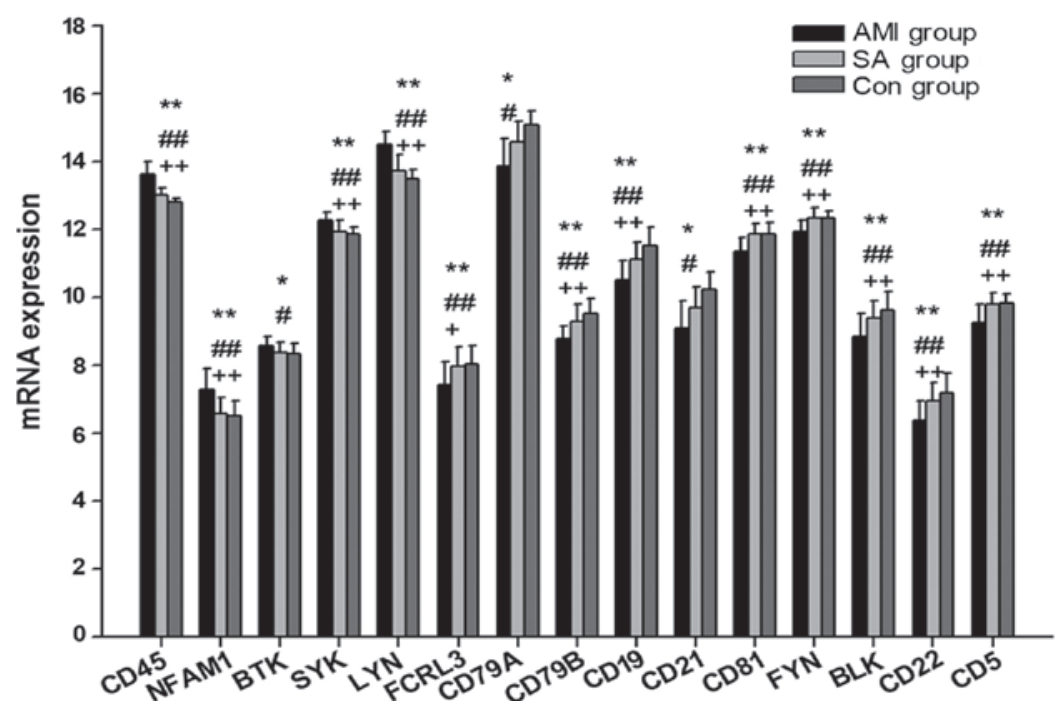

Figure 1. Significantly differential expression of genes associated with B cell antigen receptor in peripheral blood mononuclear cells from the AMI, SA and control groups. Data are presented as the mean \pm standard deviation. ${ }^{*} \mathrm{P}<0.05,{ }^{* *} \mathrm{P}<0.01$ pair comparison among all groups; ${ }^{*} \mathrm{P}<0.05$, ${ }^{\# \#} \mathrm{P}<0.01 \mathrm{AMI}$ vs. con group; ${ }^{+} \mathrm{P}<0.05,{ }^{++} \mathrm{P}<0.01$ AMI vs. SA group. AMI, acute myocardial infarction; SA stable angina; Con, control.

compared with the SA and control groups. There was no significant difference in the mRNA expression levels of genes associated with B2 cell activation between the SA and control groups.
mRNA expression levels of regulatory genes associated with $B$ cell activation. In PBMCs from the AMI, SA and control groups, the expression levels of 11 regulatory genes associated with $\mathrm{B}$ cell activation were examined (Table V; 
Table III. Expression of genes associated with T-independent B cell activation.

\begin{tabular}{|c|c|c|c|c|c|c|c|}
\hline \multirow[b]{2}{*}{ Gene ID } & \multicolumn{3}{|c|}{ Gene expression $^{\mathrm{a}}$} & \multicolumn{4}{|c|}{ P-value } \\
\hline & AMI & $\mathrm{SA}$ & Control & All groups & AMI vs. control & AMI vs. SA & SA vs. control \\
\hline SLAMF8 & $7.90 \pm 0.40$ & $7.98 \pm 0.45$ & $7.65 \pm 0.45$ & 0.058 & 0.163 & 0.832 & 0.052 \\
\hline UBD & $2.63 \pm 0.47$ & $2.48 \pm 0.35$ & $2.35 \pm 0.25$ & 0.061 & 0.072 & 0.578 & 0.518 \\
\hline CD16 & $16.48 \pm 0.60$ & $15.70 \pm 0.56$ & $15.50 \pm 0.43$ & 0.000 & 0.000 & 0.000 & 0.580 \\
\hline CD32 & $9.76 \pm 0.65$ & $9.34 \pm 0.53$ & $9.20 \pm 0.35$ & 0.004 & 0.006 & 0.033 & 0.708 \\
\hline CD180 & $6.82 \pm 0.40$ & $6.81 \pm 0.33$ & $6.87 \pm 0.41$ & 0.884 & 0.928 & 0.994 & 0.884 \\
\hline LILRA1 & $11.90 \pm 0.25$ & $11.40 \pm 0.26$ & $11.40 \pm 0.34$ & 0.000 & 0.000 & 0.000 & 0.999 \\
\hline TLR9 & $7.14 \pm 0.36$ & $6.71 \pm 0.32$ & $6.75 \pm 0.26$ & 0.000 & 0.001 & 0.000 & 0.890 \\
\hline
\end{tabular}

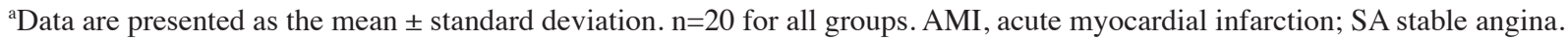

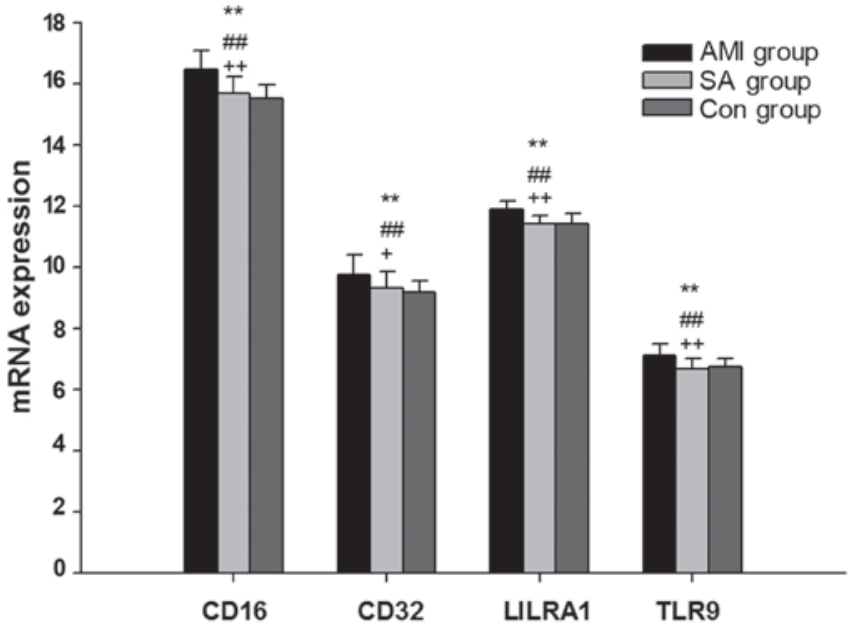

Figure 2. Significantly differential expression of genes associated with T-independent B cell activation in peripheral blood mononuclear cells from the AMI, SA and control groups. Data are presented as the mean \pm standard deviation. ${ }^{* *} \mathrm{P}<0.01$ pair comparison among all groups; ${ }^{\#} \mathrm{P}<0.01 \mathrm{AMI}$ vs. con group; ${ }^{+} \mathrm{P}<0.05,{ }^{++} \mathrm{P}<0.01 \mathrm{AMI}$ vs. SA group. AMI, acute myocardial infarction; SA stable angina; Con, control.

Fig. 4), 8 of which exhibited significant differences between all groups $(\mathrm{P}<0.05)$. In patients with $\mathrm{AMI}$, the expression levels of LILRB1, LILRA3 (P<0.05), CR1, LILRB2, LILRB3 and VAV1 $(\mathrm{P}<0.01)$ were significantly increased, whereas the expression of CS1 and IL4I1 were significantly reduced $(\mathrm{P}<0.05)$, compared with the levels in the control group. When compared with the SA group patients, the mRNA levels of CR1, LILRB2, LILRB3 and VAV1 were significantly upregulated in patients with AMI $(\mathrm{P}<0.01)$, while CS1 and IL4I1 mRNAs were significantly downregulated $(\mathrm{P}<0.05)$. There were no significant differences in the gene expression levels of regulators of $\mathrm{B}$ cell activation between patients with SA and control subjects.

\section{Discussion}

The BCR is composed of a membrane-bound immunoglobulin (Ig) sheathed by an $\operatorname{Ig} \alpha / \operatorname{Ig} \beta$ heterodimer. The receptor is critical in mediating the development and activation of B cells (16). Ig recognizes antigens, and the induced signals are transmitted by $\operatorname{Ig} \alpha(\mathrm{CD} 79 \mathrm{~A})$ and $\operatorname{Ig} \beta$. It was previously reported that high CD45 expression may reduce the expression of the BAFF and inhibit $\mathrm{B}$ cell survival $(17,18)$. Furthermore, in vivo studies in mice indicated that overexpression of NFAM1 may severely impair early B cell development (19,20). LYN and FCRL3 appear to mediate positive and negative signaling during $\mathrm{B}$ cell activation $(21,22)$, with a genetic ablation study indicating that LYN has an important inhibitory role in B cell signaling (23). In addition, CD19, CD21, CD81 and FYN are B cell co-receptors that enhance BCR signal transduction (24-26). By contrast, the B cell specific Src-family kinase, BLK, and CD5, which specifically bind the ligand of B cell surface Ig, are dispensable during B cell development and activation $(27,28)$.

In patients with AMI, the expression levels of CD45, NFAM1 and LYN were significantly increased, while CD79A, CD79B, CD19, CD21, CD81, FYN, BLK and CD5 were significantly decreased compared with the control group (Fig. 1). The results of the current study indicate that the expression of mRNAs associated with BCR signals were downregulated in patients with AMI, possibly leading to inhibition of B cell activation and development. A comparison between SA patients and the control group demonstrated no significant difference in the mRNA levels of genes involved in BCR antigen recognition, which indicates that there may be differential BCR antigen recognition activity in patients with AMI and SA.

B1 cells are considered to function in the innate response to infection by viruses and bacteria, and typically demonstrate preferential responses to T cell-independent antigens $(10,12)$. Among the 7 B1 cell-associated genes investigated, the expression levels of CD16, CD32, LILRA1 and TLR9 mRNAs were significantly upregulated in PBMCs from AMI patients compared with the SA and control groups (Fig. 2). Previous studies have demonstrated that Fc $\gamma$ receptors CD16 and CD32 may influence the growth and differentiation of B cells $(29,30)$. LILRA1 mRNA transcripts were detected in B cells and the LILRA1 protein has been observed to activate cells by associating with the $\gamma$ chain of Fc $\gamma$ receptors $(31,32)$. Furthermore, previous studies demonstrated that human B cells were activated by a TLR 9 agonist $(33,34)$. It was therefore proposed that 
Table IV. Expression of genes associated with T-dependent B cell activation.

\begin{tabular}{|c|c|c|c|c|c|c|c|}
\hline \multirow[b]{2}{*}{ Gene ID } & \multicolumn{3}{|c|}{ Gene expression ${ }^{\mathrm{a}}$} & \multicolumn{4}{|c|}{ P-value } \\
\hline & AMI & SA & Control & All groups & AMI vs. control & AMI vs. SA & SA vs. control \\
\hline ICOSL & $7.96 \pm 0.48$ & $8.32 \pm 0.35$ & $8.59 \pm 0.34$ & 0.000 & 0.000 & 0.005 & 0.092 \\
\hline BTLA & $6.57 \pm 0.63$ & $6.64 \pm 0.66$ & $6.48 \pm 0.57$ & 0.726 & 0.904 & 0.926 & 0.704 \\
\hline CD20 & $8.83 \pm 0.40$ & $9.37 \pm 0.53$ & $9.45 \pm 0.40$ & 0.000 & 0.000 & 0.001 & 0.852 \\
\hline CD28 & $8.12 \pm 0.49$ & $8.75 \pm 0.64$ & $8.69 \pm 0.40$ & 0.001 & 0.002 & 0.005 & 0.926 \\
\hline CD37 & $12.20 \pm 0.27$ & $12.30 \pm 0.26$ & $12.38 \pm 0.20$ & 0.214 & 0.249 & 0.317 & 0.988 \\
\hline CD40 & $6.56 \pm 0.45$ & $6.99 \pm 0.38$ & $7.07 \pm 0.30$ & 0.000 & 0.000 & 0.003 & 0.789 \\
\hline CD43 & $10.00 \pm 0.51$ & $10.60 \pm 0.34$ & $10.70 \pm 0.30$ & 0.000 & 0.000 & 0.000 & 0.425 \\
\hline CD72 & $6.35 \pm 0.45$ & $6.84 \pm 0.47$ & $6.97 \pm 0.50$ & 0.000 & 0.000 & 0.007 & 0.667 \\
\hline CD80 & $5.20 \pm 1.25$ & $5.26 \pm 1.31$ & $5.73 \pm 1.00$ & 0.308 & 0.340 & 0.986 & 0.425 \\
\hline CD86 & $6.64 \pm 0.61$ & $6.94 \pm 0.43$ & $6.87 \pm 0.50$ & 0.165 & 0.335 & 0.167 & 0.911 \\
\hline CD97 & $12.9 \pm 0.49$ & $12.3 \pm 0.48$ & $12.30 \pm 0.20$ & 0.000 & 0.000 & 0.001 & 1.000 \\
\hline CD226 & $8.68 \pm 0.48$ & $8.87 \pm 0.27$ & $8.80 \pm 0.40$ & 0.300 & 0.589 & 0.275 & 0.839 \\
\hline CD276 & $2.05 \pm 0.10$ & $2.24 \pm 0.30$ & $2.41 \pm 0.30$ & 0.120 & 0.213 & 0.145 & 0.976 \\
\hline LY9 & $8.35 \pm 0.34$ & $8.84 \pm 0.20$ & $8.94 \pm 0.28$ & 0.000 & 0.000 & 0.000 & 0.507 \\
\hline CTLA4 & $4.68 \pm 0.46$ & $4.89 \pm 0.34$ & $4.76 \pm 0.26$ & 0.201 & 0.760 & 0.178 & 0.521 \\
\hline EMR2 & $11.62 \pm 0.61$ & $10.60 \pm 0.58$ & $10.30 \pm 0.46$ & 0.000 & 0.000 & 0.000 & 0.175 \\
\hline TNFSF4 & $7.26 \pm 0.56$ & $6.79 \pm 0.53$ & $7.05 \pm 0.59$ & 0.051 & 0.324 & 0.053 & 0.324 \\
\hline TNFSF9 & $3.88 \pm 0.87$ & $3.20 \pm 0.88$ & $3.47 \pm 0.65$ & 0.054 & 0.136 & 0.930 & 0.063 \\
\hline PD1 & $8.96 \pm 0.41$ & $9.49 \pm 0.49$ & $9.30 \pm 0.40$ & 0.001 & 0.042 & 0.001 & 0.469 \\
\hline SLAMF1 & $8.62 \pm 0.31$ & $9.36 \pm 0.32$ & $9.20 \pm 0.43$ & 0.000 & 0.000 & 0.000 & 0.336 \\
\hline
\end{tabular}

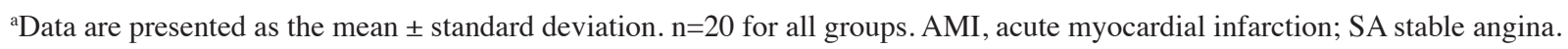

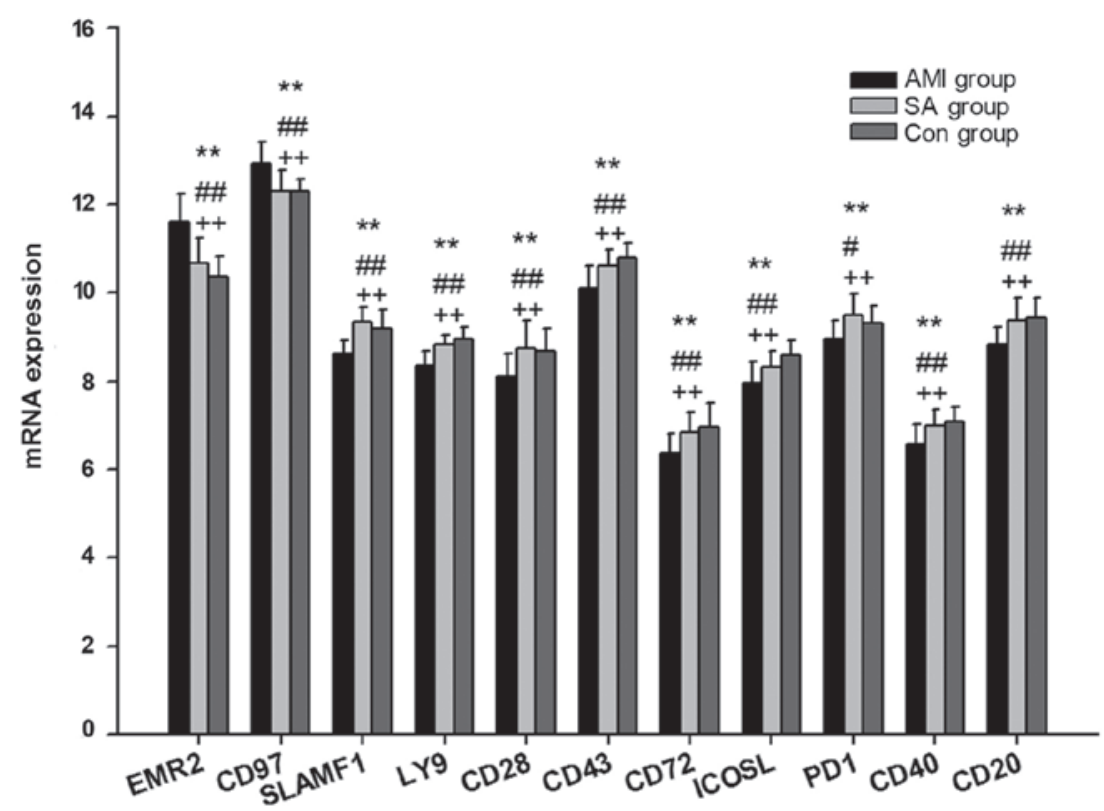

Figure 3. Significantly differential expression of genes associated with T-dependent B cell activation in peripheral blood mononuclear cells from the AMI, SA and control groups. Data are presented as the mean \pm standard deviation. ${ }^{* *} \mathrm{P}<0.01$ pair comparison among all groups; ${ }^{\#} \mathrm{P}<0.05$, ${ }^{\# \#} \mathrm{P}<0.01 \mathrm{AMI}$ vs. con group; ${ }^{++} \mathrm{P}<0.01$ AMI vs. SA group. AMI, acute myocardial infarction; SA stable angina; Con, control.

B1 cell activation is enhanced in patients with AMI, suggesting that an innate-like immune response occurs in AMI. However, there was no significant difference in B1 cell-associated gene expression between the SA patients and the control group. Thus, the results suggest that B1 cell activity is different in AMI and SA. 
Table V. Gene expression of regulators associated with B cell activation.

\begin{tabular}{|c|c|c|c|c|c|c|c|}
\hline \multirow[b]{2}{*}{ Gene ID } & \multicolumn{3}{|c|}{ Gene expression ${ }^{\mathrm{a}}$} & \multicolumn{4}{|c|}{ P-value } \\
\hline & AMI & SA & Control & All groups & AMI vs. control & AMI vs. SA & SA vs. control \\
\hline CR1 & $8.75 \pm 0.55$ & $7.71 \pm 0.71$ & $7.51 \pm 0.62$ & 0.000 & 0.000 & 0.000 & 0.577 \\
\hline BAFF & $10.35 \pm 0.38$ & $10.00 \pm 0.45$ & $9.78 \pm 0.29$ & 0.070 & 0.059 & 0.111 & 0.055 \\
\hline LILRB1 & $7.75 \pm 0.43$ & $7.60 \pm 0.29$ & $7.45 \pm 0.35$ & 0.034 & 0.025 & 0.398 & 0.359 \\
\hline LILRB2 & $13.93 \pm 0.5$ & $13.10 \pm 0.43$ & $13.09 \pm 0.39$ & 0.000 & 0.000 & 0.000 & 0.879 \\
\hline LILRB3 & $16.09 \pm 0.46$ & $15.30 \pm 0.48$ & $15.11 \pm 0.32$ & 0.000 & 0.000 & 0.000 & 0.313 \\
\hline LILRB4 & $5.66 \pm 0.58$ & $5.28 \pm 0.62$ & $5.55 \pm 0.60$ & 0.132 & 0.830 & 0.123 & 0.343 \\
\hline LILRA3 & $8.31 \pm 1.27$ & $7.84 \pm 0.94$ & $7.32 \pm 0.93$ & 0.017 & 0.012 & 0.346 & 0.272 \\
\hline LAIR1 & $9.79 \pm 0.34$ & $9.81 \pm 0.29$ & $9.85 \pm 0.22$ & 0.819 & 0.817 & 0.988 & 0.890 \\
\hline VAV1 & $12.41 \pm 0.30$ & $12.00 \pm 0.31$ & $12.03 \pm 0.21$ & 0.000 & 0.000 & 0.001 & 0.893 \\
\hline $\mathrm{CS} 1$ & $11.19 \pm 0.57$ & $11.61 \pm 0.42$ & $11.67 \pm 0.51$ & 0.007 & 0.010 & 0.025 & 0.941 \\
\hline IL4I1 & $7.50 \pm 0.50$ & $7.92 \pm 0.44$ & $8.16 \pm 0.51$ & 0.000 & 0.000 & 0.022 & 0.276 \\
\hline
\end{tabular}

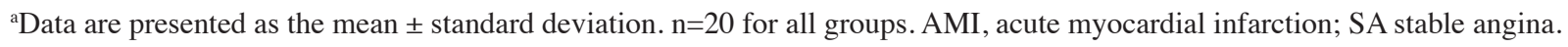

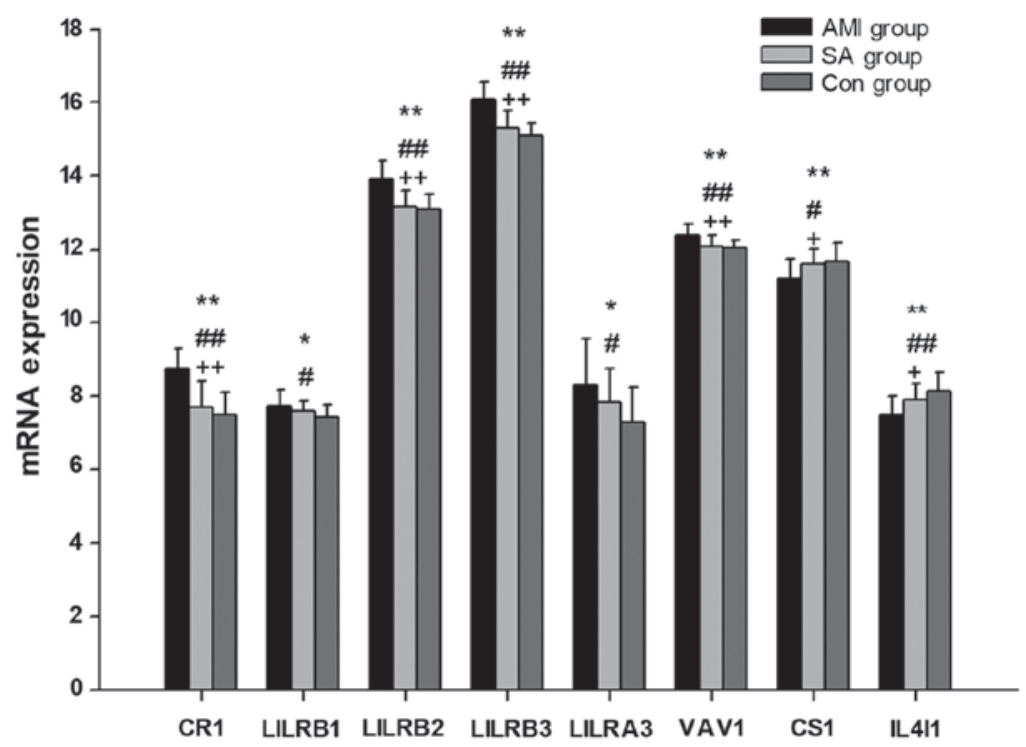

Figure 4. Significantly differential gene expression of regulators involved in B cell activation in peripheral blood mononuclear cells from the AMI, SA and control groups. Data are presented as the mean \pm standard deviation. ${ }^{*} \mathrm{P}<0.05,{ }^{* *} \mathrm{P}<0.01$ pair comparison among all groups; ${ }^{\#} \mathrm{P}<0.05$, ${ }^{\# \#} \mathrm{P}<0.01 \mathrm{AMI}$ vs. con group; ${ }^{+} \mathrm{P}<0.05,{ }^{++} \mathrm{P}<0.01$. AMI vs. SA group. AMI, acute myocardial infarction; SA stable angina; Con, control.

B2 cells are important in B cell-specific humoral immunity (35). Among the 20 genes examined, the mRNA expression levels of EMR2 and CD97 were significantly upregulated in AMI patients compared with the SA and control groups (Fig. 3). EMR2 and CD97 are important for the interaction between T cells and B cells (36). The SLAM family, including SLAMF1 and LY9, together with CD28 and CD43, are essential in the development and maturation of B cells, and the control of the humoral immune response (37-39). The ICOS-ICOSL and PD1-PDL pathways are important for the stimulation of effector T cell and B2 cell responses (40-42). The association between CD40 and CD40L, which are expressed on the surface of activated $\mathrm{T}$ cells, promotes the activation of B cells (43). CD20 is a B cell-specific integral membrane protein that regulates $B$ cell proliferation (44). In the present study, the levels of SLAMF1, LY9, CD28, CD43, ICOSL, PD1, CD40 and CD20 mRNAs were lower in AMI patients compared with the control group (Fig. 3). These results demonstrate that the $\mathrm{T}$ cell-B cell interaction was weakened during the B2 cell activation in AMI. No significant differences were observed between the SA and control group patients, indicating that the potential insufficiency of the humoral response only occurred in the B2 subset during AMI.

Among the 11 regulatory genes associated with B cell activation examined, the mRNA expression levels of CR1, LILRB2, LILRB3, LILRA3 and VAV1 were significantly increased in AMI patients compared with those in the SA and control groups (Fig. 4). CR1 is an inhibitor of BCR-mediated $B$ cell activation (45) and LILRB negatively regulates the activation of antigen presenting cells $(46,47)$. Additionally, it 
has been previously demonstrated that mice lacking VAV1 exhibit defects in B cell activation (48). Previous studies also observed that CS1 promotes the proliferation of human B lymphocytes and increases the expression of autocrine cytokines $(20,49-51)$. Thus, the results of the current study indicate that B cell activation is inhibited in patients with AMI. Furthermore, there was no significant difference in the mRNA levels of genes associated with B cell activation between the SA and control groups.

During the current study, standard gene testing procedures and appropriate statistical analyses were performed using randomly selected patients and controls, however, the study was not without limitations. Notably, there was an age difference between patients with AMI/SA and the control subjects. It is unclear whether aging affected the humoral response or whether the young control group had a normal immunity status compared with AMI/SA patients. However, the current data indicates that there was no significant difference in humoral immunity between patients with SA and the control group. The second limitation was the enhanced B1 cell activation observed in patients with AMI. B1 cells are a minor component of the total B cell population, which is a part of the innate immune response and produces natural antibodies. Thus, further in vitro studies are required to elucidate the pathological mechanisms of antigen processing pathways in the B cell system.

In conclusion, the statistical downregulation of genes associated with the BCR, B2 cells and B cell regulators in patients with AMI indicates that there is a weakened T cell-B cell interaction, as well as reduced B2 cell activation and development, during AMI. Notably, there were no statistical differences in the expression levels of B cell-associated genes between the SA and control groups, demonstrating that B2 cell dysfunction is only observable in AMI and not in SA. B2 cells are considered to be the conventional B lymphocytes, producing and regulating the antibody-mediated humoral immunity $(12,13)$. Consequently, improving B2 cell-mediated humoral immunity may be considered as a potential target for the treatment of patients with AMI.

\section{Acknowledgements}

The present study was supported by the Shanghai Traditional Chinese Medicine 3-Year Development Program (2014-2016; grant no. ZY3-CCCX-3-3047).

\section{References}

1. Murray CJ, Vos T, Lozano R, Naghavi M, Flaxman AD, Michaud C, Ezzati M, Shibuya K, Salomon JA, Abdalla S, et al: Disability-adjusted life years (DALYs) for 291 diseases and injuries in 21 regions, 1990-2010: A systematic analysis for the Global Burden of Disease Study 2010. Lancet 380: 2197-2223, 2012.

2. Kyaw T, Tay C, Khan A, Dumouchel V, Cao A, To K, Kehry M, Dunn R, Agrotis A, et al: Conventional B2 B cell depletion ameliorates whereas its adoptive transfer aggravates atherosclerosis. J Immunol 185: 4410-4419, 2010.

3. Clement M, Guedj K, Andreata F, Morvan M, Bey L, Khallou-Laschet J, Gaston AT, Delbosc S, Alsac JM, Bruneval P, et al: Control of the $\mathrm{T}$ follicular helper-germinal center $\mathrm{B}$-cell ax is by $\mathrm{CD} 8^{+}$regulatory $\mathrm{T}$ cells limits atherosclerosis and tertiary lymphoid organ development. Circulation 131: 560-570, 2015.
4. Paigen B, Morrow A, Holmes PA, Mitchell D and Williams A: Quantitative assessment of atherosclerotic lesions in mice. Atherosclerosis 68: 231-240,1987.

5. Thorp E, Cui D, Schrijvers DM, Kuriakose G and Tabas I: Mertk receptor mutation reduces efferocytosis efficiency and promotes apoptotic cell accumulation and plaque necrosis in atherosclerotic lesions of apoe-/- mice. Arterioscler Thromb Vasc Biol 28: 1421-1428, 2008.

6. Tsiantoulas D, Diehl CJ, Witztum JL and Binder CJ: B cells and humoral immunity in atherosclerosis. Circ Res 114: 1743-1756, 2014.

7. Kyaw T, Tay C, Krishnamurthi S, Kanellakis P, Agrotis A, Tipping P, Bobik A and Toh BH: Bla B lymphocytes are atheroprotective by secreting natural $\operatorname{IgM}$ that increases $\operatorname{IgM}$ deposits and reduces necrotic cores in atherosclerotic lesions. Circ Res 109: 830-840, 2011

8. Kyaw T, Tay C, Hosseini H, Kanellakis P, Gadowski T, MacKay F, Tipping P, Bobik A and Toh BH: Depletion of B2 but not B1a B cells in BAFF receptor-deficient ApoE mice attenuates atherosclerosis by potently ameliorating arterial inflammation. PLoS One 7: e29371, 2012.

9. Ait-Oufella H, Herbin O, Bouaziz JD, Binder CJ, Uyttenhove C, Laurans L, Taleb S, Van Vré E, Esposito B, Vilar J, et al: B cell depletion reduces the development of atherosclerosis in mice. $\mathrm{J}$ Exp Med 207: 1579-1587, 2010.

10. Janeway CA Jr, Travers P, Walport M and Shlomchik MJ: Immunobiology. 5th edition. Garland Science, New York, 2001.

11. Sage AP and Mallat Z. Multiple potential roles for B cells in atherosclerosis. Ann Med 46: 297-303, 2014

12. Cerutti A, Cols M, Puga I: Marginal zone B cells: Virtues of innate-like antibody-producing lymphocytes. Nat Rev Immunol 13: 118-132, 2013.

13. Tsiantoulas D, Sage AP, Mallat Z and Binder CJ: Targeting B cells in atherosclerosis: Closing the gap from bench to bedside. Arterioscler Thromb Vasc Biol 35: 296-302, 2015.

14. Thygesen K, Alpert JS, Jaffe AS, Simoons ML, Chaitman BR and White HD; Joint ESC/ACCF/AHA/WHF Task Force for Universal Definition of Myocardial Infarction: Third universal definition of myocardial infarction. J Am Coll Cardiol 60: 1581-1598, 2012

15. Livak KJ and Schmittgen TD: Analysis of relative gene expression data using real-time quantitative PCR and the 2(-Delta Delta C(T)) method. Methods 25: 402-408, 2001.

16. Kurosaki T: Regulation of BCR signaling. Mol Immunol 48: 1287-1291, 2011.

17. Huntington ND, Xu Y, Puthalakath H, Light A, Willis SN, Strasser A and Tarlinton DM: CD45 links the B cell receptor with cell survival and is required for the persistence of germinal centers. Nat Immunol 7: 190-198, 2006.

18. Zikherman J, Doan K, Parameswaran R, Raschke W and Weiss A: Quantitative differences in CD45 expression unmask functions for CD45 in B-cell development, tolerance, and survival. Proc Natl Acad Sci USA 109: E3-E12, 2012.

19. Ohtsuka M, Arase H, Takeuchi A, Yamasaki S, Shiina R, Suenaga T, Sakurai D, Yokosuka T, Arase N, Iwashima M, et al: NFAM1, an immunoreceptor tyrosine-based activation motif-bearing molecule that regulates B cell development and signaling. Proc Natl Acad Sci USA 101: 8126-8131, 2004.

20. Lv W, Duan Q, Wang L, Gong Z, Yang F and Song Y: Expression of B-cell-associated genes in peripheral blood mononuclear cells of patients with symptomatic pulmonary embolism. Mol Med Rep 11: 2299-2305, 2015.

21. Scapini P, Pereira S, Zhang H and Lowell CA: Multiple roles of Lyn kinase in myeloid cell signaling and function. Immunol Rev 228: 23-40, 2009.

22. Li FJ, Schreeder DM, Li R, Wu J and Davis RS: FCRL3 promotes TLR9-induced B-cell activation and suppresses plasma cell differentiation. Eur J Immunol 43: 2980-2992, 2013.

23. Stepanek O, Draber P, Drobek A, Horejsi V and Brdicka T: Nonredundant roles of Src-family kinases and Syk in the initiation of B-cell antigen receptor signaling. J Immunol 190: 1807-1818, 2013.

24. Barrington RA, Schneider TJ, Pitcher LA, Mempel TR, Ma M, Barteneva NS and Carroll MC: Uncoupling CD21 and CD19 of the B-cell coreceptor. Proc Natl Acad Sci USA 106: 14490-14495, 2009.

25. van Zelm MC, Smet J, Adams B, Mascart F, Schandené L, Janssen F, Ferster A, Kuo CC, Levy S, van Dongen JJ and van der Burg M: CD81 gene defect in humans disrupts CD19 complex formation and leads to antibody deficiency. J Clin Invest 120: 1265-1274, 2010. 
26. Barua D, Hlavacek WS and Lipniacki TA: Computational model for early events in B cell antigen receptor signaling: Analysis of the roles of Lyn and Fyn. J Immunol 189: 646-658, 2012.

27. Texido G, Su IH, Mecklenbräuker I, Saijo K, Malek SN, Desiderio S, Rajewsky K and Tarakhovsky A: The B-cell-specific Src-family kinase Blk is dispensable for B-cell development and activation. Mol Cell Biol 20: 1227-1233, 2000.

28. Pospisil R, Silverman GJ, Marti GE, Aruffo A, Bowen MA and Mage RG: CD5 is A potential selecting ligand for B-cell surface immunoglobulin: A possible role in maintenance and selective expansion of normal and malignant B cells. Leuk Lymphoma 36: 353-365, 2000.

29. de Andres B, Mueller AL, Verbeek S, Sandor M and Lynch RG: A regulatory role for Fcgamma receptors CD16 and CD32 in the development of murine B cells. Blood 92: 2823-2829, 1998.

30. Horejs-Hoeck J, Hren A, Mudde GC and Woisetschläger M Inhibition of immunoglobulin $\mathrm{E}$ synthesis through $\mathrm{Fc}$ gammaRII (CD32) by a mechanism independent of B-cell receptor co-cross-linking. Immunology 115: 407-415, 2005.

31. Tedla N, An H, Borges L, Vollmer-Conna U, Bryant K, Geczy C and McNeil HP: Expression of activating and inhibitory leukocyte immunoglobulin-like receptors in rheumatoid synovium: Correlations to disease activity. Tissue Antigens 77: 305-316, 2011

32. Fanger NA, Borges L and Cosman D: The leukocyte immunoglobulin-like receptors (LIRs): A new family of immune regulators. J Leukoc Biol 66: 231-236, 1999.

33. Hanten JA, Vasilakos JP, Riter CL, Neys L, Lipson KE, Alkan SS and Birmachu W: Comparison of human B cell activation by TLR7 and TLR9 agonists. BMC Immunol 9: 39, 2008.

34. Yamazaki K, Yamazaki T, Taki S, Miyake K, Hayashi T, Ochs HD and Agematsu K: Potentiation of TLR9 responses for human naïve B-cell growth through RP105 signaling. Clin Immunol 135: 125-136, 2010.

35. Hilgendorf I, Theurl I, Gerhardt LM, Robbins CS, Weber GF, Gonen A, Iwamoto Y, Degousee N, Holderried TA, Winter $\mathrm{C}$, et al: Innate response activator B cells aggravate atherosclerosis by stimulating $\mathrm{T}$ helper- 1 adaptive immunity. Circulation 129: 1677-1687, 2014.

36. Kwakkenbos MJ, Pouwels W, Matmati M, Stacey M, Lin HH, Gordon S, van Lier RA and Hamann J: Expression of the largest CD97 and EMR2 isoforms on leukocytes facilitates a specific interaction with chondroitin sulfate on B cells. J Leukoc Biol 77: 112-119, 2005.

37. De Salort J, Sintes J, Llinàs L, Matesanz-Isabel J and Engel P: Expression of SLAM (CD150) cell-surface receptors on human B-cell subsets: From pro-B to plasma cells. Immunol Lett 134: 129-136, 2011

38. Reiter R and Pfeffer K: Impaired germinal centre formation and humoral immune response in the absence of CD28 and interleukin-4. Immunology 106: 222-228, 2002.

39. Galindo-Albarrán AO, Ramírez-Pliego O, Labastida-Conde RG, Melchy-PérezEI,Liquitaya-Montiel A,Esquivel-Guadarrama FR, Rosas-Salgado G, Rosenstein Y and Santana MA: CD43 signals prepare human $\mathrm{T}$ cells to receive cytokine differentiation signals. J Cell Physiol 229: 172-180, 2014.
40. Chen J, Wang F, Cai Q, Shen S, Chen Y, Hao C and Sun J: A novel anti-human ICOSL monoclonal antibody that enhances IgG production of $\mathrm{B}$ cells. Monoclon Antib Immunodiagn Immunother 32: 125-131, 2013.

41. Greenwald RJ, Freeman GJ and Sharpe AH: The B7 family revisited. Annu Rev Immunol 23: 515-548, 2005.

42. Mak TW, Shahinian A, Yoshinaga SK, Wakeham A, Boucher LM, Pintilie M, Duncan G, Gajewska BU, Gronski M, Eriksson U, et al: Costimulation through the inducible costimulator ligand is essential for both $\mathrm{T}$ helper and $\mathrm{B}$ cell functions in T cell-dependent B cell responses. Nat Immunol 4: 765-772, 2003.

43. Nadeau PJ, Roy A, Gervais-St-Amour C, Marcotte MÈ, Dussault N and Néron S: Modulation of CD40-activated B lymphocytes by $\mathrm{N}$-acetylcysteine involves decreased phosphorylation of STAT3. Mol Immunol 49: 582-592, 2012.

44. Uchida J, Lee Y, Hasegawa M, Liang Y, Bradney A, Oliver JA, Bowen K, Steeber DA, Haas KM, Poe JC and Tedder TF: Mouse CD20 expression and function. Int Immunol 16: 119-129, 2004.

45. Józsi M, Prechl J, Bajtay Z and Erdei A: Complement receptor type 1 (CD35) mediates inhibitory signals in human B lymphocytes. J Immunol 168: 2782-2788, 2002.

46. Young NT, Waller EC, Patel R, Roghanian A, Austyn JM and Trowsdale J: The inhibitory receptor LILRB1 modulates the differentiation and regulatory potential of human dendritic cells. Blood 111: 3090-3096, 2008

47. HoWangYin KY, Loustau M, Wu J, Alegre E, Daouya M, Caumartin J, Sousa S, Horuzsko A, Carosella ED and LeMaoult J: Multimeric structures of HLA-G isoforms function through differential binding to LILRB receptors. Cell Mol Life Sci 69: 4041-4049, 2012.

48. Fujikawa K, Miletic AV, Alt FW, Faccio R, Brown T, Hoog J, Fredericks J, Nishi S, Mildiner S, Moores SL, et al: Vav1/2/3-null mice define an essential role for Vav family proteins in lymphocyte development and activation but a differential requirement in MAPK signaling in T and B cells. J Exp Med 198: 1595-1608, 2003.

49. Lee JK, Mathew SO, Vaidya SV, Kumaresan PR and Mathew PA: CS1 (CR ACC, CD319) induces proliferation and autocrine cytokine expression on human B lymphocytes. J Immunol 179: 4672-4678, 2007.

50. Kim JR, Mathew SO, Patel RK, Pertusi RM and Mathew PA: Altered expression of signalling lymphocyte activation molecule (SLAM) family receptors CS1 (CD319) and 2B4 (CD244) in patients with systemic lupus erythematosus. Clin Exp Immunol 160: 348-358, 2010.

51. Hsi ED, Steinle R, Balasa B, Szmania S, Draksharapu A, Shum BP, Huseni M, Powers D, Nanisetti A, Zhang Y, et al: CS1, a potential new therapeutic antibody target for the treatment of multiple myeloma. Clin Cancer Res 14: 2775-2784, 2008. 